\title{
Aproximaciones al discurso de lo paisa en Colombia
}

Approaches to the paisa speech in Colombia

RESUMEN

En Colombia, las personas oriundas del departamento de Antioquia y de la región denominada "Eje Cafetero", son conocidas en el país por el apelativo coloquial dado a sus habitantes: paisas. Este trabajo describe las formas en que se ha presentado la idea de lo paisa en textos académicos e investigaciones producidos durante las últimas dos décadas en la región, buscando enunciar los elementos, discursos y repertorios que se le atribuyen y que actualmente conforman ese relato de lo que se conoce como paisa. Además de identificar dichos aspectos, cuestionamos las implicaciones de estas representaciones producidas y reproducidas por la academia y sus impactos en ámbitos políticos, económicos y sociales, estableciendo distinciones y jerarquías entre algunas regiones que componen la nación.

Palabras clave: Antioquia, Colombia, producción académica, identidades regionales, paisas.

\section{Abstract}

In Colombia, people from Antioquia and the region known as the "coffee triangle" are known in the country for the colloquial nickname that their inhabitants receive: paisas. This work describes the ways in which the idea of "paisa" has been presented in the academic texts and research
América Larraín-GonzÁlez

Profesora Asociada, Facultad

de Ciencias Humanas y

Económicas de la Universidad

Nacional de Colombia

Sede Medellín. Grupo de

Investigación Historia,

Trabajo, Sociedad y Cultura.

$\square$ aylarraingo@unal.edu.co

(1) ORCID: 0000-0002-5783-2815

$\approx$ Google Scholar

Pedro José Madrid-Garcés

Candidato a Doctor en

Ciencias Humanas y Sociales,

Universidad Nacional de

Colombia, Sede Medellín.

Grupo de Investigación Historia,

Trabajo, Sociedad y Cultura .

\ pjmadridg@unal.edu.co

(1) ORCID: 0000-0002-3848-2880

$\checkmark$ Google Scholar 
carried out during the last two decades in the region, seeking to state the elements, discourses and repertoires attributed to it and that currently make up this account of what is known as paisa. In addition to identifying these aspects, we question the implications of these representations produced and reproduced by the academy and their impacts in political, economic and social spheres, establishing distinctions and hierarchies between some of the regions of the nation.

Keywords: Antioquia, Colombia, academic production, regional identities, paisas.

\section{Introducción}

ste trabajo busca identificar los discursos y las referencias
producidos y reproducidos desde la academia respecto a lo que
podríamos denominar provisoriamente la identidad paisa.

Esta búsqueda y selección se realizó en bases de datos como Ebsco, Scielo y WebScience, privilegiando textos que tuvieran una perspectiva antropológica o que fueran producidos por académicos con algún grado de formación en antropología, es decir, con estudios (pregrado o posgrado) en el área o campos afines.

Así mismo, tuvimos en cuenta que pertenecieran o se encontraran asentados en la región estudiada y que se hubieran publicado en los últimos 20 años. Se escogieron ocho documentos en total.

A partir del análisis de dichos textos, pretendemos describir cómo se ha definido y descrito lo paisa. Este trabajo no aspira desde ningún punto de vista identificar los orígenes del uso del vocablo, sino sus usos actuales, que tienen como base un repertorio de ideas e imágenes reconocidas nacionalmente como atributos de lo paisa.

Es pertinente mencionar la dificultad que implica asumir este rótulo como una categoría de análisis, una vez que el mismo no da cuenta de manera estricta, de un grupo social homogéneo o asentado en un territorio específico. De igual forma, es de resaltar, que las distintas definiciones sobre lo paisa, hacen parte de un repertorio arraigado en el sentido común nacional. En esa medida, transitaremos aquí entre esas diferentes versiones de lo paisa que consolidan el espectro de sus definiciones en el ámbito cotidiano y en el mundo académico. 
En este artículo, en aras de intentar una delimitación provisoria para nuestro abordaje, nos referiremos a los paisas como parte de los pobladores de la antigua "Gran Antioquia", la cual comporta las actuales divisiones administrativas y departamentales de Antioquia, Caldas, Risaralda, Quindío y norte del Valle del Cauca.

El documento está estructurado en cuatro momentos. Primero, profundizaremos en la categoría paisa, a partir de las definiciones disponibles, intentando describir sus alcances, a quienes integra, sus usos y paradojas. En un segundo momento, evocaremos las descripciones y características de lo paisa identificadas en los textos analizados. En tercer lugar, teniendo como base dichas referencias, intentaremos establecer las continuidades, cambios y elementos paradójicos en estas producciones académicas, buscando señalar las intermitencias en la reproducción de tales discursos. Finalmente, procederemos a problematizar estas descripciones y discursos de lo paisa, mostrando la relación entre el nombre o rótulo paisa, la identidad regional y la producción de conocimiento.

Nos interesa, de esta forma, señalar dicha relación como una manifestación de poder en sí misma (Hall, 2010), que legitimada desde la academia, ha incidido y modelado las relaciones de las regiones y comunidades del país, reificando ciertos patrones de conducta como parte de un mito nacional, donde los paisas cuentan con un lugar privilegiado que incide claramente en las relaciones políticas y de poder en el país ${ }^{1}$.

\section{Los paisas}

Para el caso colombiano, en el transcurso de la historia nacional, se han construido relatos sobre las regiones, los departamentos y los circuitos culturales que amalgaman comunidades y sectores sociales completos, distinguiendo las particularidades y características de las gentes que habitan cada geografía (Martí y Pozo, 2000; Posada, 2011).

En dichas evocaciones, priman las referencias a las virtudes y a las hazañas de ciertos héroes locales o determinados colectivos, que generalmente contrastan con los estereotipos negativos a partir de los cuales son caracterizados otros grupos y regiones, generando distinciones marcadas y jerarquías en un mismo Estado nacional.

\footnotetext{
Un ejemplo de ello, relativamente reciente, fue la votación nacional conocida como Referendo - Plebiscito por la Paz (2016), que buscaba establecer la aprobación de los procesos y acuerdos de paz entre la guerrilla de las FARC y el gobierno nacional, y que fue desaprobada mayoritariamente en el departamento de Antioquia, región con una marcada tendencia política conservadora y de derecha, donde la influencia del expresidente Álvaro Uribe Vélez, es muy evidente y reconocida.
} 
Esto, ha tenido como resultado el ejercicio de poder de unos sobre otros, tratándose, grosso modo, de una réplica de lo que fuera el evolucionismo como paradigma intelectual del siglo XIX, donde se mitificó a la civilización occidental, siendo el parámetro de clasificación para otras formas e historias de organización social alrededor del mundo. En Colombia -y en América Latina-, los tintes racistas de dicha jerarquía son ampliamente reconocidos.

Para el caso aquí estudiado, tenemos una evocación mítica de lo paisa, que según Fajardo (1966), resume un arquetipo del proyecto político nacional de la siguiente manera:

Cuando se habla del paisa las cualidades que más a menudo se le atribuye son: ascetismo, positivismo, activismo, movilidad geográfica, sentido práctico, reserva, sentido comercial, frugalidad, laboriosidad, afición por el dinero, fidelidad conyugal, maneras democráticas, alta motivación hacia el éxito, optimismo, religiosidad, sentido de independencia, regionalismo, afición al juego, tradicionalismo, método, orden, adversidad, neutralidad afectiva, puritanismo sexual, creencia en el progreso, igualitarismo, predominio de la orientación hacia el futuro, afición al riesgo calculado, truculencia, locuacidad e hipersensibilidad acerca del tiempo. (Fajardo, 1966, p. 26)

Dichas características que se le atribuyen a los paisas, son comúnmente reproducidas y replicadas en diferentes producciones académicas ${ }^{2}$, consolidando una especie de estabilidad en el discurso sobre lo paisa, cuya identidad está arraigada en la idea de ser el pueblo "verraco ${ }^{3}$ y pujante de la nación" (Hermelin, 1991, p. 13).

Distintas revisiones históricas sitúan a los paisas en la región de los Andes centrales colombianos, específicamente en los departamentos de Antioquia, Caldas, Risaralda, Quindío y norte del Valle del Cauca. Ocampo (1993), Fajardo (1966) y López de Mesa (1970) señalan que sus pobladores son producto de la fusión de dos elementos etno-culturales: el español y el indígena ${ }^{4}$.

\footnotetext{
Ver textos de Villegas Botero (2003) sobre el paisa como un pueblo especial, diferente y auténtico.

El nombre verraco hace alusión a la valentía, audacia y bravura, aparece en distintos textos aquí abordados con ortografía diferente. En algunos textos se utiliza "berraco". Optamos por mantener la grafía original de cada texto, anotando que en cualquier caso, la alusión es siempre la misma.

Dicha referencia evidencia claramente la ausencia de lo afro en el discurso regional.
} 


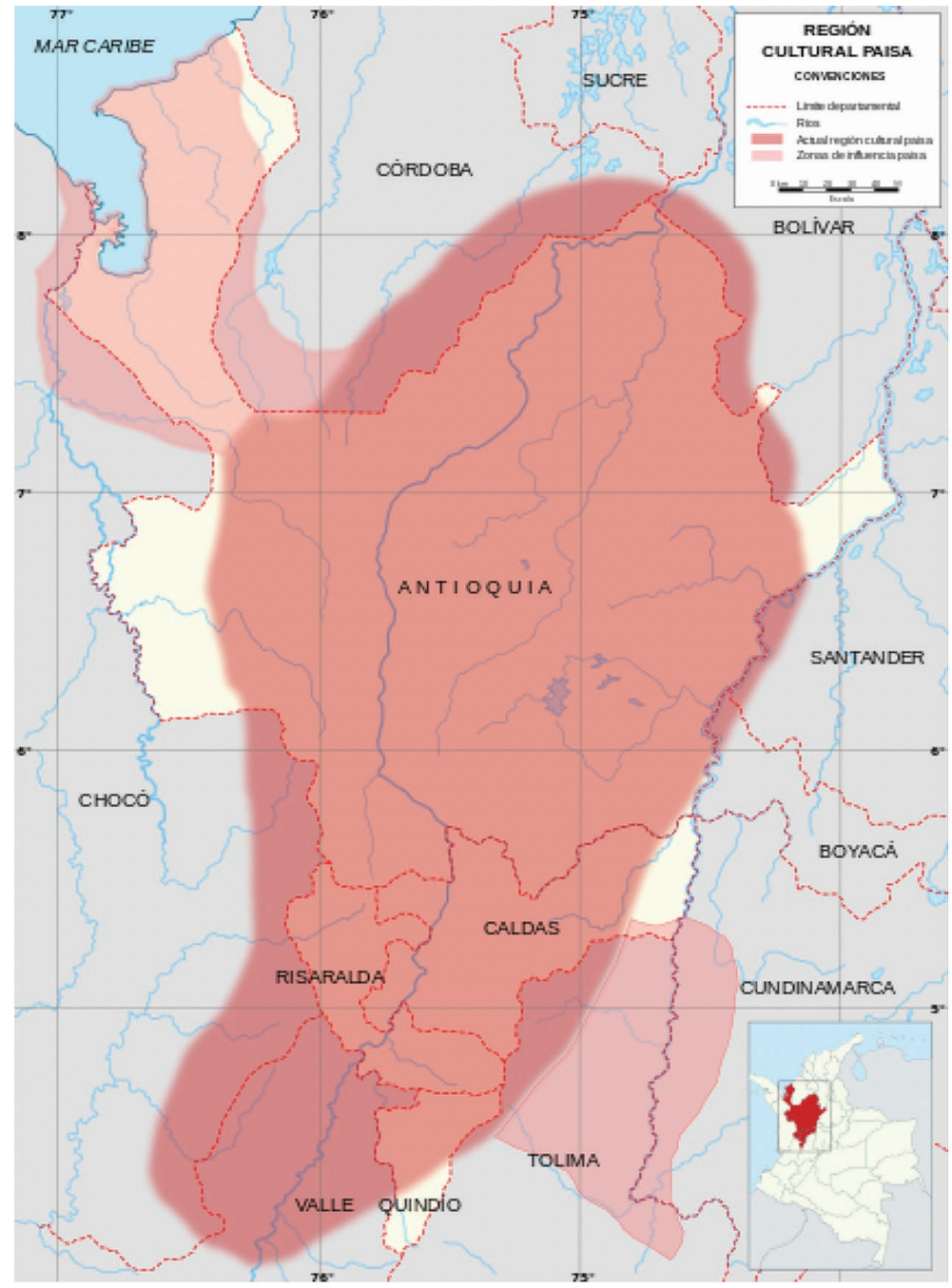

Figura 1. Región cultural paisa (2012)

5 Imagen tomada del geoportal de mapas del IGAC: http://geoportal.igac.gov.co/mapas_de_colombia/IGAC/ Tematicos2012/RegionesCulturales.pdf 


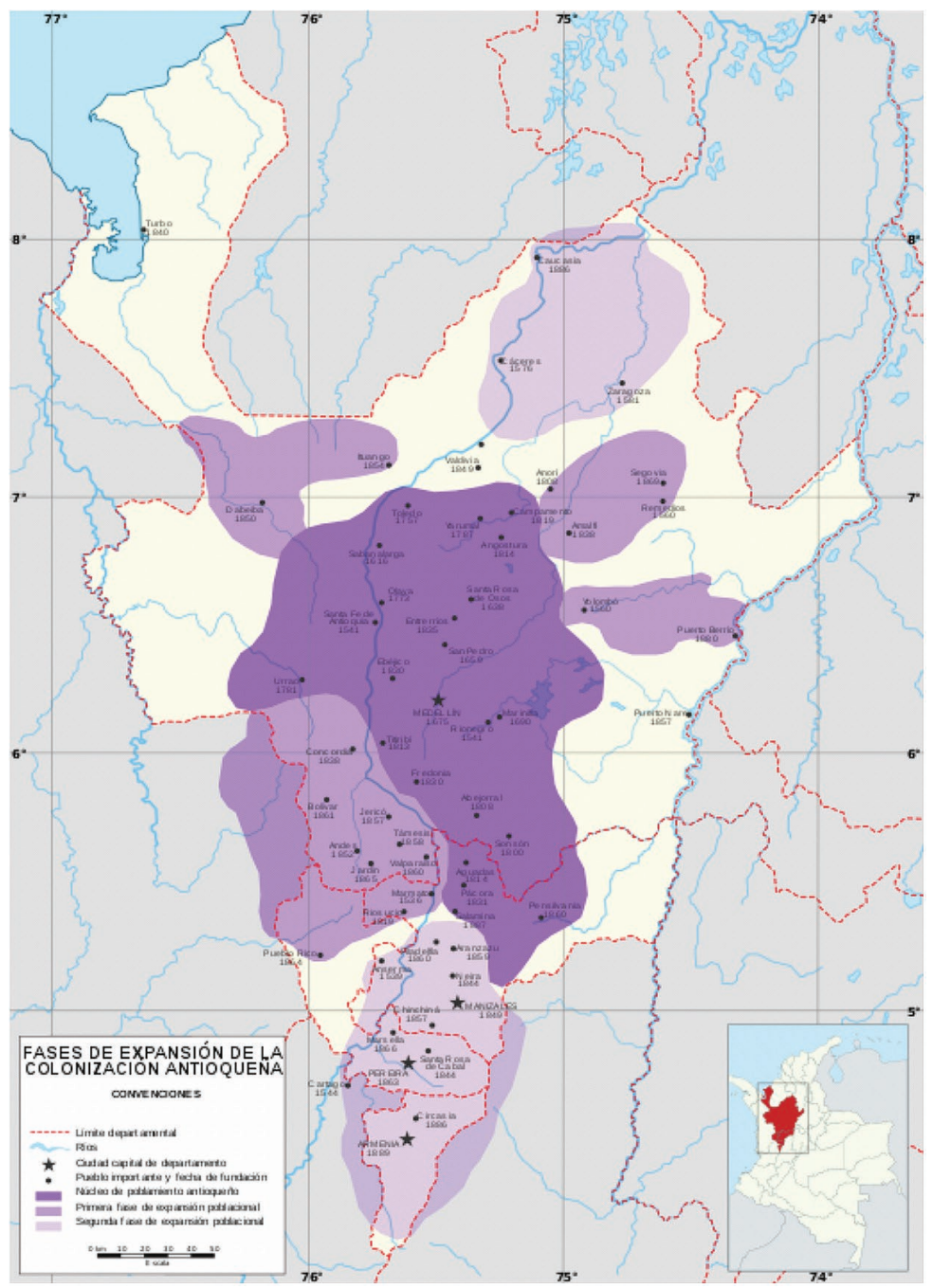

Figura 2. Expansión poblacional durante la colonización antioqueña (2013) .

Ahora bien, como se muestra en las imágenes, hablar de un territorio paisa es complicado pues su área de influencia abarca relaciones con por lo menos diez departamentos. Este hecho nos lleva necesariamente a matizar la unanimidad y aparente homogeneidad que se aduce en diversas descripciones de su identidad.

Aquí encontramos por un lado zonas que concentran a los "paisas originarios" (Escobar, 1997) que apelan ser los "verdaderos paisas" o "paisas

\footnotetext{
6 Imagen tomada de: https://commons.wikimedia.org/wiki/File\%3AMapa_de_la_colonizaci\%C3\%B3n_ antioque\%C3\%Bla_(expansi\%C3\%B3n_poblacional).svg
} 
colonizadores" (Centro de Antioquia, Caldas, Quindío y Risaralda- en rojo); y por otro lado, a los paisas por "adhesión", es decir, los zonas y comunidades que fueron sumadas territorial y culturalmente al circuito cultural paisa, como resultado de la influencia de estos últimos en determinadas zonas tales como: Urabá, norte de los departamentos del Tolima y Valle del Cauca (Nates Cruz, 2009), que son, curiosamente, los territorios anexados por las vías de hecho, resultado del proceso de colonización y expansión antioqueña en el siglo XIX- en rosado en imagen 1 y en púrpura en imagen 2.

Tras situar - por lo menos provisoriamente- el territorio paisa, esbozaremos las características que se les han atribuido en algunos relatos académicos. Estrada Ochoa (2017) señala que:

En todas las regiones nos dicen paisas porque durante muchos años, hacia la época de nuestros bisabuelos y tatarabuelos, la costumbre en el trato entre personas desconocidas no era usar la formula "señor", ni de "amigo", sino sencillamente "paisano", este uso de la palabra ha desaparecido, pero continua vigente como una forma de gentilicio. (Estrada Ochoa, 2017, p. 77)

En esta referencia, aparece la palabra paisa no como fuente de la que habría surgido el vocablo paisa, un tipo de uso cotidiano para hablar al vecino, una evocación de un pasado común económico y social de los antioqueños y afines.

Sin embargo, al profundizar en la denominación paisa, es evidente que no se trata de un nombre o adjetivo que apele a algún tipo de unidad. Esto es particularmente llamativo no apenas en relación con el resto del país, sino paradójicamente en el territorio que es abrazado por esta denominación o gentilicio, como lo son los centros capitales de esta región cultural imaginada: Medellín, Manizales, Pereira y Armenia, especialmente. Entre estos lugares, existen relaciones que jerarquizan y atribuyen características particulares a sus habitantes y dichas singularidades están asociadas a prácticas culturales territoriales específicas de cada centro.

Tal sería el caso de las diferencias establecidas por Nates (2009) entre los paisas caldenses y los paisas antioqueños; entre los paisas caucanos y "originarios" referidas por Vásquez Lara (2013), o de aquello estudiado por Pimienta Betancur (2007) respecto a las zonas de influencia e interacción territorial antioqueña con los departamentos de Bolívar y Sucre. Sin embargo, las distinciones referidas por estos autores no son problematizadas ni cuestionadas, dejando de lado un importante foco 
de análisis de las prácticas de poder imbuidas en las clasificaciones y descripciones sociales de cada uno de estos territorios. Sobre estos temas y autores nos detendremos adelante.

$\mathrm{Al}$ estudiar lo paisa como categoría clasificatoria, nos encontramos frente al establecimiento de límites territoriales, remembranzas de la gesta expansionista de la Colonización Antioqueña ${ }^{7}$, donde los sujetos son descritos a partir de sus loables lazos de vecindad y convivencia y de sus facultades anímicas para sortear las adversidades. Dichas características son claramente estereotipos, versiones incompletas de los habitantes que integran estas regiones. En los relatos sobre lo paisa ha habido una omisión e invisibilización sistemáticas de la población nativa indígena y de las comunidades negras, que fueron excluidas por completo de la versión oficial.

De otra parte, hay una notoria ausencia en los relatos académicos sobre los paisas, a las historias de violencias sistemáticas y a las formas de ilegalidad (incluyendo el narcotráfico) que tuvieron su cuna y se producen a diario en la región. Poco o nada se dice del relativamente reciente expansionismo que ha llevado a los paisas a ocupar y usurpar territorios a lo largo y ancho del país. Tampoco se han estudiado los vínculos de esta gran región y sus habitantes con organizaciones armadas ilegales, por mencionar apenas algunos aspectos que no hacen parte de ese relato oficial sobre lo paisa.

Lo anterior es digno de ser resaltado, pues el recorte aquí empleado hace referencia a textos académicos regionales relativamente recientes, que en buena medida se han dedicado a reproducir una versión simplificada y esencialista de un territorio y sus pobladores, como mostraremos a continuación.

\section{Relatos y discursos sobre lo paisa en los textos académicos}

Los temas de la identidad paisa y las características del pueblo antioqueño han sido asuntos frecuentemente estudiados por parte de los autores y académicos de la región. Entre estos se destacan las investigaciones históricas, sociológicas y antropológicas, siendo el enfoque histórico predominante.

\footnotetext{
Este hecho histórico ha sido ampliamente estudiado y descrito por diversos investigadores, algunos de los cuales son referenciados en el presente artículo. Sin embargo, es pertinente advertir al lector, que aquí mencionaremos el tema apenas como parte de los elementos que componen el discurso de lo paisa. De igual manera, nos interesa señalar, que tales discursos no se reducen a textos y que en el ámbito de las artes, ha habido aportes significativos, tal vez uno de los más paradigmáticos sea el reconocido óleo "Horizontes" (1913), autoría de Francisco Antonio Cano.
} 
En lo que se refiere a la construcción de la historia oficial de los territorios de la colonización antioqueña, prima lo que podríamos denominar un discurso contemplativo de la hazaña representada por el ejercicio de "dominar la cordillera central andina y proveerla de descendientes laboriosos" (López de Mesa, 1962, p. 37)

En estas producciones académicas se referencian los elementos y prácticas recurrentes - casi repetitivas- que dan vida y conforman los relatos que conocemos sobre los paisas. Aspectos como el trabajo en la minería, su incansable laboriosidad; su capacidad de dominio del escarpado territorio; la importancia de la religión católica y la conformación de familias numerosas, son temas reproducidos de manera invariable, componiendo un repertorio obligatorio para hablar de los paisas, inclusive desde la academia.

El paisa, sería así un sujeto representado esencialmente de modo masculino, como abridor de caminos, colonizador, minero, buen negociante, perspicaz y más recientemente emprendedor y empresario. En estos relatos hay una evidente ausencia y ocultación de aspectos como los conflictos territoriales del proceso colonizador, el exterminio y expropiación de las poblaciones nativas, la esclavitud y las posteriores formas laborales regionales que han favorecido y reproducido importantes diferencias sociales entre sus habitantes, gracias al ejercicio abusivo del poder de unos sobre otros, en muchas ocasiones amparado por un discurso religioso católico ${ }^{9}$.

Como se mencionó en la introducción, para elaborar esta reflexión seleccionamos ocho textos que son resultado de indagaciones antropológicas y trabajos de corte etnográfico sobre las características y patrones identitarios de los paisas en los diferentes territorios de la denominada "región cultural antioqueña".

Establecimos dentro de esta delimitación como textos de corte antropológico, aquellos producidos por antropólogos de formación y profesión, al igual que aquellos estudios que se auto referenciaban como exploraciones etnográficas situadas dentro del campo de la antropología,

Textos como los de Poveda Ramos (1988), Twinam (1982), Ospina Rodríguez (1989) y Arango Mejía (1942) también son claros referentes de la exaltación de este pueblo desde los discursos históricos.

Un ejemplo de esta cuestión es abordado en el trabajo de Arango (1991), quien estudia de manera rigurosa las relaciones de poder establecidas en el campo de la industria textil antioqueña, amparadas y promovidas por la iglesia católica: el problema del patronato y la religiosidad implicadas en los procesos económicos regionales, que tuvieron como consecuencia la conformación de una masa obrera femenina y sumisa que estaba sometida a un innegable control físico y moral al servicio de los intereses de los "pujantes" empresarios antioqueños. 
textos que se presentan de manera esquemática en la siguiente tabla, para proceder con su análisis minucioso.

Tabla 1. Producción académica de corte antropológico sobre los paisas, 2000-2017.

\begin{tabular}{clc}
\hline Año & Título & Autor \\
\hline 2006 & $\begin{array}{l}\text { El elogio de la dificultad como narrativa de la identidad regional en } \\
\text { Antioquia }\end{array}$ & Arcila Estrada, M. \\
\hline 2007 & $\begin{array}{l}\text { La configuración de la identidad local en la diversidad cultural: el } \\
\text { caso de Caucasia }\end{array}$ & Pimienta Betancur, A. \\
\hline 2009 & $\begin{array}{l}\text { Pensar el mundo, practicar el entorno. Etnografías y reflexiones } \\
\text { desde una antropología de las territorialidades }\end{array}$ & Nates Cruz, B. \\
\hline 2012 & $\begin{array}{l}\text { Cuatro aportes desde la antropología para comprender la } \\
\text { emigración }\end{array}$ & Hernández Pulgarín, G. \\
\hline 2012 & El paisa y sus orígenes & Saldarriaga, R. \\
\hline 2013 & $\begin{array}{l}\text { Los imaginarios de la colonización antioqueña desde 1860 hasta } \\
\text { 1930 en la zona del Eje Cafetero una visión antropológica }\end{array}$ & Vásquez Lara, C. \\
\hline 2013 & En blanco y negro: Paisas y chocoanos en Quibdó & Serna Botero, S. \\
\hline 2017 & Fogón Antioqueño & Estrada Ochoa, J. \\
\hline
\end{tabular}

Fuente: Elaboración propia.

El primer texto seleccionado "El elogio de la dificultad como narrativa de la identidad regional en Antioquia", de Arcila Estrada (2006), se trata de un artículo de investigación donde la autora perfila las ideas construidas por los escritores antioqueños del siglo XIX en lo que se configuró como el discurso común de los "modos de ser", "carácter" y "temperamento" de los antioqueños. Dicho discurso tendría como narrativa predominante la gran capacidad de este pueblo para enfrentar la dificultad y con proeza superar cada obstáculo.

En el desarrollo del texto, la autora centra su análisis de la representación de los paisas a partir de la gesta de la colonización antioqueña, en especial a partir de los elementos de superación de la adversidad y de la heroicidad que caracterizarían al paisa en su lucha para enfrentar las condiciones naturales montañosas y escarpadas del territorio. Este motivo va a ser reiterado constantemente en los escritos históricos y sociológicos de los siglos XIX y XX.

Para la autora, la construcción narrativa que han hecho los intelectuales antioqueños de los orígenes de su pueblo se funda en el relato que tiene al escarpado paisaje de montaña como protagonista, $\mathrm{y}$, en consecuencia, se hace reiterada referencia a la tenacidad y valor requeridos para "enfrentar un medio tan agreste y hostil como el que 
les correspondió habitar"10. En dicho relato, los colonos "salieron victoriosos frente a la lucha de este pueblo con esas dificultades del medio, cimentando los sentimientos de orgullo y valoración que forjó (sic) el "carácter" dinámico y emprendedor que se les adjudica" (Arcila Estrada, 2006, p. 40).

Uno de los datos interesantes del trabajo de Arcila Estrada, es que dichas representaciones sociales, propias de los antioqueños, surgieron en contraposición a las ideas vigentes en décadas anteriores, producidas por representantes del poder colonial quienes, a diferencia de lo que sucede actualmente, juzgaban y criticaban a la población por considerarla un "mísero pueblo de provincia... vagos y perezosos" (Arcila Estrada, 2006, p. 2).

La autora concluye en su trabajo, que la personalidad del paisa está claramente marcada por su relación con el espacio, privilegiando en el discurso ciertas características colectivas que obedecen a lo que ella denomina "adaptación al medio natural y al entorno", apuntando a una suerte de determinismo geográfico. Esto, según señala, habría ayudado a consolidar su autoimagen de pueblo con facilidad para superar las adversidades, permitiendo así hablar de una cierta personalidad regional (Arcila Estrada, 2006, p. 70).

El siguiente texto analizado, autoría de Pimienta Betancur (2007), titulado "La configuración de la identidad local en la diversidad cultural: el caso de Caucasia", se aborda el asunto de la identidad paisa en confrontación con las comunidades periféricas y el choque resultado de la expansión antioqueña, particularmente en el municipio de Caucasia, que limita con las sabanas del Caribe colombiano.

En este texto, el autor intenta ampliar la localización geográfica de los paisas, bajo la denominación de "paisas adheridos" en contraste con lo que serían los "paisas originarios"11. Se trataría, según su definición, de comunidades que han vivido cierto tipo de mestizaje cultural. El autor se refiere concretamente a los elementos paisas que habrían confluido con los costeños - nombre bajo el que se designa en el país de manera coloquial a los pobladores del litoral atlántico-.

10 En este sentido, es pertinente detenerse en el uso del lenguaje que hace la autora, silenciando hechos como la invasión, apropiación y usurpación de tierras perpetradas por los antioqueños, toda vez que al hablar de habitar, como un acto espontáneo, hay necesariamente una omisión y selección funcional del relato de ocupación territorial y despojo que sufrieron los habitantes nativos. Aquí el escenario en cuestión aparece como un espacio salvaje, despoblado, virgen; propicio para ser desbravado y habitado.

11 Es decir, los pertenecientes el centro de Antioquia, Caldas, Risaralda y Quindío. 
En este ejercicio, Pimienta Betancur retrata la representación de los paisas bajo las características reproducidas por los discursos de las élites antioqueñas en el siglo XX, concretamente aquellas relacionadas con lo que se conoce como la "raza antioqueña" o el "ethos sociocultural antioqueño". Según el autor, se trataría de un conjunto de valores y prácticas sociales a las que se les habría dado el nombre de antioqueñidad, un relato mítico que con adeptos y opositores, es reconocido y aprobado en los ámbitos regional y nacional (Pimienta Betancur, 2007, p. 70).

Para Pimienta Betancur, las prácticas de este discurso influyeron de tal manera en las comunidades periféricas ${ }^{12}$ que para principios del siglo XX, este discurso era la base del imaginario de las élites paisas, y se concebía la importancia de las regiones en una especie de escala que iba del centro (Medellín), a las regiones más alejadas como Caucasia o Urabá.

Otro de los elementos que el autor referencia, es el asunto de la jerarquización de las regiones y los lugares propicios para la reproducción de dicho "ethos sociocultural antioqueño" como el Oriente y el Suroeste antioqueños, que según apunta:

Eran concebidas como aptas para la reproducción del "ser antioqueño", con los consabidos valores morales cristianos, de diferencia cultural y capitalista. Otras regiones como Magdalena Medio, Urabá, Nordeste y Bajo Cauca eran percibidas como altamente inapropiadas, pues allí no se vivían esos valores y por el contrario se creía que era común la unión libre, el chamanismo, la brujería y la prostitución. (Pimienta Betancur, 2007, p. 70)

Finalmente, el autor habla de la funcionalidad enmascaradora de las representaciones sobre los paisas en contraposición con el circuito cultural costeño, aduciendo que la idealización cultural, promovida por las elites antioqueñas, es de doble vía, pues a la vez que se alimenta de una suerte de supervaloración del ego social, también excluye y sataniza al otro, al que se separa del comportamiento ideal dictado por los valores ya mencionados, mediante una asociación a lo "anormal". Es decir, ese "otro" está alejado de toda norma social, es inmoral, criminal, corrupto, con visos de insubordinación y sin respeto por la autoridad (Pimienta Betancur, 2007, p. 71).

Por otro lado, el tercer texto revisado, autoría de Nates Cruz (2009), "Pensar el mundo, practicar el entorno. Etnografías y reflexiones desde

12 Respecto a la centralidad del poder político y económico del departamento de Antioquia. 
una antropología de las territorialidades", es un artículo de investigación donde se esboza y problematiza la relación de los paisas con el territorio.

Para Nates Cruz (2009), entre los denominados paisas de los Andes centrales de Colombia, "el mundo" es aquello que requiere ser colonizado como medio de adquisición de poder económico y político. Bajo esta mirada, la autora plantea que entre los paisas el mundo no colonizado, "el monte", es "inferior", un tipo de lugar inconcluso y sinsentido (Nates Cruz, 2009, p. 281).

Un aspecto interesante que rescata la autora, y que se ha silenciado o mutilado de los discursos predominantes sobre los paisas, es el asunto del narcotráfico, tema que, según señala, estaría a la par de otros elementos del conjunto de imágenes y objetos constitutivos de lo que se reconoce en el imaginario común como la cultura paisa.

En su investigación, Nates Cruz cuestiona el discurso oficial de lo antioqueño y las réplicas de este relato predominante ${ }^{13}$, mostrando cómo habría una exagerada idealización de la identidad cultural paisa que omite buena parte de sus diferencias y particularidades internas. Al respecto:

Los paisas habitantes del centro de Colombia, entre los departamentos de Antioquia, Caldas, Risaralda, Quindío y norte del Valle del Cauca, son vistos por el resto de los colombianos como "colonizadores" y como "berracos", término cuyo uso social alude a "aguerrido", "valiente". Los colonizadores por excelencia de todo este grupo son los paisas de Antioquia quienes detentan lo que se ha llamado en Colombia la Colonización antioqueña ${ }^{14} \ldots$ (Nates Cruz, 2009, p. 288)

La autora describe también las diferencias identificadas entre los mismos paisas. Los de Antioquia se consideran y son considerados por los demás paisas como los "verdaderos paisas"; los de Caldas (capital Manizales), de Risaralda (capital Pereira) y del Quindío (capital Armenia), son los paisas colonizados. El resto serían al parecer, según indica la

13 Como se mencionó atrás, dicho discurso fue producto de las elites regionales que buscaban hacer frente al estereotipo de provinciano vago y miserable que se tenía del antioqueño antes del siglo XIX (Arcila Estrada, 2006).

14 Señala la autora que dicha Colonización antioqueña fue animada por varias disposiciones jurídicas, comenzando por la ley de ocupación de tierras del 13 de octubre de 1821; por la ley 31 de 1823 sobre "apertura de caminos"; por el decreto del 27 de mayo de 1842 en el que se estipula el derecho a casa y labranza (incipiente configuración de la finca) y, finalmente, por la ley 61 de 1874 de los Estados Unidos de Colombia, con la estipulación del derecho a habitar tierras sin medida de extensión, siempre y cuando fuesen habitadas y cultivadas (Nates Cruz, 2009, p. 288). 
autora, paisas de menor categoría o "adheridos", como resultado de la interacción con "los paisas antioqueños y los paisas colonizados".

Otro de los textos analizados, titulado "El paisa y sus orígenes", autoría de Saldarriaga (2012), se encuentra a medio camino entre un libro y una enciclopedia. Se trata del resultado de diferentes investigaciones antropológicas y arqueológicas en la región cultural antioqueña desarrolladas por el autor durante 40 años.

A diferencia de los otros textos identificados, en éste se critica y se cuestiona el encubrimiento histórico de los elementos y características indígenas y negros que constituyen a los pobladores de la antigua Antioquia. A pesar de su crítica, el autor acaba retomando un discurso de la condición étnica sui generis de los paisas, atribuyéndoles características sociales y elementos anímicos particulares.

Para Saldarriaga, "la historia paisa debe ser reescrita, toda vez que ha sido frecuentemente enmascarada, camuflada, desfigurada y mutilada. Con clara responsabilidad de los cronistas paisas en la reproducción de una idea desdibujada de las características propias del territorio" (Saldarriaga, 2012, p. 11).

En el texto se caracterizan y sitúan 37 etnias que serían constitutivas de los actuales paisas, entre las que se encuentran diferentes poblaciones indígenas, comunidades negras introducidas mediante el sistema esclavista y a su vez, los distintos ascendientes europeos que poblaron los territorios de la hoy reconocida región cultural paisa.

Otro de los textos que aquí analizamos, titulado "Cuatro aportes desde la antropología para comprender la emigración", de Hernández Pulgarín (2012), presenta al pueblo paisa como un pueblo migrante, de facultades diferenciales con relación al resto de integrantes del territorio nacional.

En el texto, el autor esboza los discursos construidos en torno a lo que implica ser paisa y a las características determinantes de sus prácticas sociales. Para el autor, ser paisa implica el reconocimiento colectivo de "verracos", es decir, sujetos normalmente exitosos en todas las actividades que realizan (Hernández Pulgarín, 2012, p. 37).

Para este autor, el elemento fundamental que diferencia las valorizaciones que se atribuyen a los paisas, es su carácter de migrantes, toda vez que dicha característica representaría: "reproducir el acto 
trashumante de civilizar un territorio incognito, de obtener éxito y riqueza con la realización de esa empresa tan bien ponderada socialmente" (Hernández Pulgarín 2012, p. 42).

Bajo esta misma lógica, el elemento migratorio se encuadra en la condición que es reconocida localmente del paisa como andariego, es decir, la búsqueda de esa riqueza idílica fuera de las fronteras, favorecida por su presumida condición de "verraquera", elemento que configuraría su heroicidad.

Finalmente, Hernández Pulgarín (2012) refiere que estos rasgos distintivos construidos en torno a los paisas y a la figura del "verraco", se han incorporado a la identidad nacional, expresándose sobre todo en los contextos de emigración o entre las poblaciones inmigrantes tanto en el país como fuera de él. La descripción de este autor incita a pensar en el paisa como un "colonizador por naturaleza".

De otra parte, tenemos el trabajo titulado "Los imaginarios de la colonización antioqueña desde 1860 hasta 1930 en la zona del Eje Cafetero, una visión antropológica" de Vásquez Lara (2013). El autor se interesa en el reconocimiento identitario de los colonos paisas en el Eje Cafetero, a través del análisis de un sistema de interpretaciones y de valoraciones, que provocaron una adhesión afectiva, capaz de moldear conductas o inspirar las acciones que se han gestado con la historia de la colonización antioqueña y que, en consecuencia:

han alimentado la dinámica y forjado una aura (sic) de ensoñación y de gesta a través del papel de un hombre recio, blanco, amante de la ley y de Dios, que como símbolo cumple en el proceso de construcción de una identidad colectiva sobre la antioqueñidad (paisas hoy en día). (Vásquez Lara, 2013, p. 7)

A través del texto, se hace referencia detallada a todo el proceso de colonización antioqueña, evocando características de los paisas y sus diferencias de acuerdo con el territorio que ocupan. En el desarrollo del artículo, el autor menciona las sospechosas epopeyas que desde los textos históricos se han construido en torno al proceso de expansión de los antioqueños, las cuales se han replicado sin problematización alguna a través de los discursos históricos.

Para Vásquez Lara (2013), hay cuatro características fundamentales de los paisas: lo patriarcal, lo militar, el fervor religioso y el afán por la riqueza, siendo esta última una de las características más alabadas por 
los numerosos escritores que han hecho referencia a los antioqueños. Para el autor, dichas características son fundamentales para entender las imágenes y relatos que componen el discurso de su más importante gesta histórica: la colonización antioqueña ${ }^{15}$.

En este estudio (al igual que en otros reseñados previamente), se refiere lo estratégico de determinados relatos construidos en torno a los paisas y a sus vecinos. Vásquez Lara insiste en que, para la construcción de la identidad paisa, ha sido fundamental la representación nefasta del otro $^{16}$, que, en el caso de este estudio, sería el caucano, habitante de las tierras bajas fronterizas con el río Cauca, sobre quien recaerían una serie de prejuicios y acusaciones fundamentados básicamente en sus características étnicas diferenciadas:

Las autoridades caucanas hablan de "la raza antioqueña", como grupo pujante, progresista y laborioso, con espíritu de trabajo y disciplina, con una moral pura y católica que debía hacer frente a los ateos y liberales. Esto fue dirigido a los colonizadores que vieron que su trabajo era como una especie de cruzada contra los caucanos a los que se consideraba flojos, ateos, liberales y negros. (Vásquez Lara, 2013, p. 23)

Otro de los textos aquí analizados, se titula "En blanco y negro: Paisas y chocoanos en Quibdó" (Serna Botero, 2013). Se trata de una tesis de maestría donde, al igual que en los textos de Pimienta Betancur (2007) y Vásquez Lara (2013), se estudian los relatos e imágenes sobre los paisas en regiones donde han tenido históricamente una importante influencia cultural e intervención territorial.

El caso aquí referenciado, estudia y problematiza los relatos de exaltación casi míticos de los paisas, confrontados con los desafortunados estereotipos de pobreza y carencias atribuidos a los chocoanos. En uno de los capítulos de dicha tesis, se estudia el asunto de la identidad paisa y de las características que se le han atribuido mediante los diferentes discursos académicos, tanto históricos, como sociológicos y antropológicos. La autora expone un amplio repertorio de características que han definido y modelado la propia representación de lo

15 Vale recordar al lector que estos relatos no presentan apenas un carácter escrito, y que como mencionamos atrás, han tenido en el ámbito de las artes, un espacio fecundo para la construcción y proliferación de imágenes y sonidos constitutivos de ese discurso hegemónico de lo paisa. Tal es el ya citado caso del cuadro "Horizontes" (Cano, 1913); de parte de la obra del célebre arquitecto y artista Pedro Nel Gómez, y, más recientemente, de la musicalidad local conocida como Chucu-chucu o "sonido paisa" (Parra, 2014, 2017).

16 Situación referenciada previamente en Pimienta Betancur (2007). 
antioqueño, entre las que se encuentran, una singular concepción del trabajo y de la tierra.

De igual forma, Serna Botero esboza la existencia de un "relato sobre la antioqueñidad", que ha estado determinado por elementos y prácticas de la colonización antioqueña:

Arrieros, ataviados con ruanas y carrieles, ensillaron las mulas y salieron de sus montañas por el sur a sembrar de café otras montañas: pelaron con sus machetes y labraron con sus manos el monte de lo que hoy conocemos como Caldas, Risaralda, Quindío, el norte del Tolima y el norte del Valle del Cauca. (Serna Botero, 2013, p. 24)

El último elemento citado por la autora es el reiterado devenir económico de los paisas, con referencia a Medellín como "la capital industrial de Colombia", luego de la gesta colonizadora antioqueña. Al igual que Nates Cruz (2009), la autora relata fenómenos invisibles en las representaciones académicas de los paisas, como el narcotráfico y adiciona los elementos de la violencia y criminalidad del centro de poder político y económico de los antioqueños:

El devenir económico de los antioqueños se resume ramplonamente así: pequeños mineros en la colonia -principalmente mazamorreros-, pujantes colonizadores en el siglo XIX - pero propietarios de apenas unos minifundios-, y exitosos empresarios en la primera mitad del siglo XX. El correlato moral de ese devenir resulta categórico. Como pueblo: homogéneo, cohesionado, igualitario, democrático, armónico, feliz. Como individuos: valientes, emprendedores, arriesgados, vigorosos, creativos. Tuvieron todas las condiciones para progresar, para alcanzar tamaña prosperidad. Pero como todo cambia, todo cambió. De la altísima cumbre erigida sobre el sentido de pertenencia y de diferencia, sobre el amor a la familia y el trabajo, se despeñó el "proyecto" o el "modelo" antioqueño. Primero fue la guerra bipartidista nacional, que conocemos como el periodo de La Violencia. Después estalló la "crisis contemporánea". Su clímax: entre 1985 y 1991. Medellín se volvió la capital mundial de las drogas y ostentó "el más alto índice de muertes violentas en un país donde esas cifras eran de por sí bastante elevadas" Todo cambió, Medellín llegó a ser la ciudad más peligrosa del mundo. "Metrallo", le decían. Todavía le dicen. Y también "la ciudad más innovadora". (Serna Botero, 2013, p. 26) 
Esta referencia muestra por un lado las distintas características atribuidas a los paisas mediante un discurso oficial, por ellos mismo construido; y, por otro lado, cómo se ha enmascarado y mutilado el relato sobre los paisas en distintas versiones académicas.

Finalmente, el último texto que aquí analizaremos, titulado "Fogón antioqueño", es de autoría del antropólogo Estrada Ochoa (2017), quien aborda algunos aspectos culturales, particularmente alimenticios. Es llamativo en este trabajo, que, pese a los cuestionamientos y advertencias previas de los autores aquí citados, respecto a los esencialismos, omisiones y enmascaramientos que constituyen ese relato paisa hegemónico, hay en el trabajo de este autor, una réplica ausente de crítica, de dicho relato regional que se popularizó en el siglo XX.

El autor se refiere a los paisas de la siguiente manera:

Más que aventureros somos viajeros y arriesgados. Claro está que somos simpáticos, pero más que simpáticos somos amables y, ante todo, colaboradores (con propios y extraños). No somos mentirosos, sino exagerados, bastante exagerados. Acepto que somos negociantes, y muy buenos, pero realmente somos empresarios, o mejor, emprendedores. En cuanto a lo de alegres, no pretendo refutarlo: la alegría es una virtud y convengamos que somos gente de buen humor, buenos humoristas - que no chistosos- y muy dados a la sonrisa. Lo de marrulleros suena dudoso: la verdad es que somos astutos. En lo referente a camanduleros, simplemente somos religiosos; y, en cuanto a familiares, digamos más bien que nos gusta procrear sin compasión de las mujeres. ¿Interesados? Lo que nos gusta es trabajar para conseguir plata, eso nos gusta más que Dios. Finalmente, se nos considera toscos... yo digo que somos ordinarios en el buen sentido de la palabra, es decir, no somos finos, porque tenemos un origen histórico campesino, antes que citadino. Somos más rurales que urbanos: somos montañeros. Es un hecho nuestra comarca no tiene planicies, es quebradiza, rocosa, empinada y agreste. Permítanme, entonces que yo defina a mi gente en pocas palabras: somos un pueblo sincero, recursivo y echado para adelante. Finalmente, tenemos una singular manera de hablar, con tonos, expresiones y vocablos del castellano antiguo y con un "cantaíto" que nos delata en cualquier parte del mundo. (Estrada Ochoa, 2017, p. 78)

Es curioso en este trabajo el intento del autor por ratificar los estereotipos que se asocian a los paisas, como si la representación 
de las elites antioqueñas desde el siglo XX no hubiese bastado y fuera necesario "sanear" algunos de los aspectos negativos que hoy en día se les atribuyen.

Ahora bien, luego de esbozar las características, elementos y factores estructurantes de las diferentes imágenes, relatos y discursos de lo paisa a través de los textos, abordaremos algunos asuntos de dichas producciones desde una perspectiva crítica, intentando sintetizar mediante la siguiente tabla, los elementos a partir de los cuales los autores describen a los paisas.

Tabla 2. Elementos y características de los paisas referenciados en los textos 2000-2017.

\begin{tabular}{|c|c|c|}
\hline Textos & Elementos referenciados & $\begin{array}{l}\text { Relación con textos } \\
\text { previos }^{17}\end{array}$ \\
\hline $\begin{array}{l}\text { Arcila Estrada, M. (2006). } \\
\text { El elogio de la dificultad } \\
\text { como narrativa de la } \\
\text { identidad regional en } \\
\text { Antioquia. }\end{array}$ & $\begin{array}{l}\text { Paisa: pueblo de montaña } \\
\text { Carácter y tenacidad } \\
\text { Superador de dificultades-heroico } \\
\text { El factor territorial como determinante } \\
\text { La autodefinición a partir de las proezas, como } \\
\text { mecanismo para desmontar el estereotipo existente. }\end{array}$ & $\begin{array}{l}\text { CONTINUIDAD } \\
\text { REAFIRMACIÓN }\end{array}$ \\
\hline $\begin{array}{l}\text { Pimienta Betancur, A. } \\
\text { (2007). La configuración } \\
\text { de la identidad local en } \\
\text { la diversidad cultural: el } \\
\text { caso de Caucasia }\end{array}$ & $\begin{array}{l}\text { Muestra la jerarquización y el predominio de lo paisa } \\
\text { respecto a otros grupos sociales } \\
\text { Evoca la función distintiva del constructo paisa para } \\
\text { intervenir en las comunidades "no paisas" } \\
\text { Muestra la identidad cultural del paisa como un } \\
\text { proyecto de las elites antioqueñas para el ejercicio del } \\
\text { poder político y económico. }\end{array}$ & DISCONTINUIDAD \\
\hline $\begin{array}{l}\text { Nates Cruz, B. (2009). } \\
\text { Pensar el mundo, } \\
\text { practicar el entorno. } \\
\text { Etnografías y reflexiones } \\
\text { desde una antropología } \\
\text { de las territorialidades. }\end{array}$ & $\begin{array}{l}\text { Diferencias entre los paisas } \\
\text { El paisa y la importancia de su territorio } \\
\text { La identidad paisa es en definitiva la colonización } \\
\text { antioqueña } \\
\text { La constante autodefinición de los paisas como } \\
\text { "verracos" } \\
\text { Referencia el fenómeno del narcotráfico y su ausencia } \\
\text { en el relato paisa. }\end{array}$ & $\begin{array}{l}\text { DISCONTINUIDAD } \\
\text { CRÍTICA }\end{array}$ \\
\hline $\begin{array}{l}\text { Saldarriaga, R. (2012). El } \\
\text { paisa y sus orígenes }\end{array}$ & $\begin{array}{l}\text { Es el primer texto que sitúa el problema de lo } \\
\text { indígena y lo negro entre los paisas } \\
\text { Refiere las descripciones estratégicas de los paisas y } \\
\text { sus territorios. }\end{array}$ & DISCONTINUIDAD \\
\hline $\begin{array}{l}\text { Hernández Pulgarín, G. } \\
\text { (2012). Cuatro aportes } \\
\text { desde la antropología } \\
\text { para comprender la } \\
\text { emigración }\end{array}$ & $\begin{array}{l}\text { La migración es el factor estructurante del relato } \\
\text { paisa } \\
\text { Las demás valorizaciones están intrínsecamente } \\
\text { relacionadas con la actividad migratoria. }\end{array}$ & $\begin{array}{l}\text { CONTINUIDAD } \\
\text { REAFIRMACIÓN }\end{array}$ \\
\hline
\end{tabular}

17 Este punto hace referencia a la relación del documento analizado, con textos anteriores sobre la misma temática, pero que están por fuera del recorte establecido para esta aproximación. 


\begin{tabular}{|c|c|c|}
\hline Textos & Elementos referenciados & $\begin{array}{l}\text { Relación con textos } \\
\text { previos }^{18}\end{array}$ \\
\hline $\begin{array}{l}\text { Vásquez Lara, C. (2013). } \\
\text { Los imaginarios de la } \\
\text { colonización antioqueña } \\
\text { desde } 1860 \text { hasta } 1930 \\
\text { en la zona del Eje } \\
\text { Cafetero una visión } \\
\text { antropológica }\end{array}$ & $\begin{array}{l}\text { Lo patriarcal, lo militar, el fervor religioso y el afán de } \\
\text { la riqueza son fundamentales para análisis de lo paisa } \\
\text { Referencia el racismo presente en el relato oficial de } \\
\text { la identidad paisa } \\
\text { La construcción académica de los paisas sería un } \\
\text { ejercicio de poder. }\end{array}$ & $\begin{array}{l}\text { DISCONTINUIDAD } \\
\text { PERO REAFIRMA } \\
\text { CIERTOS } \\
\text { REPERTORIOS }\end{array}$ \\
\hline $\begin{array}{l}\text { Serna Botero, S. (2013). } \\
\text { En blanco y negro: } \\
\text { Paisas y chocoanos en } \\
\text { Quibdó }\end{array}$ & $\begin{array}{l}\text { Describe al paisa en su relación con la tierra } \\
\text { (acumulación) } \\
\text { Señala la existencia de un "relato paisa" de auto } \\
\text { exaltación } \\
\text { Referencia la violencia y el narcotráfico como } \\
\text { interferencias del relato paisa hegemónico } \\
\text { Se muestra el "paisa originario" como el comerciante } \\
\text { migrante por excelencia. }\end{array}$ & $\begin{array}{l}\text { DISCONTINUIDAD } \\
\text { CRÍTICA }\end{array}$ \\
\hline $\begin{array}{l}\text { Estrada Ochoa, J. (2017). } \\
\text { Fogón antioqueño }\end{array}$ & $\begin{array}{l}\text { Descripción del paisa a partir de atributos positivos: } \\
\text { orgulloso de su tierra, amable, colaborador, exagerado, } \\
\text { negociante, empresario, emprendedor, alegre, de buen } \\
\text { humor, religioso, astuto, laborioso, trabajador, etc. } \\
\text { El territorio como factor determinante de la } \\
\text { personalidad - determinismo geográfico } \\
\text { No hay críticas ni cuestionamientos de ningún tipo. }\end{array}$ & $\begin{array}{l}\text { RETROCESO } \\
\text { CONTINUIDAD } \\
\text { REAFIRMACIÓN }\end{array}$ \\
\hline
\end{tabular}

Fuente: Elaboración propia.

\section{Elementos de las descripciones académicas de los paisas}

Toda descripción es un relato, una versión parcial sometida a las particularidades históricas, sociales, económicas y políticas de un determinado momento. Todo discurso, versión y relato obedece a intereses de grupos sociales, de individuos y de los colectivos a los que estos pertenecen. Este artículo no es la excepción.

Para el tema y el período abordados aquí, vemos como las versiones académicas de las paisas producidas en su propio entorno regional, han cumplido el cometido de fundar, alimentar y reproducir elementos, características y hechos que constituyen el marco referencial de lo que podría llamarse una "identidad paisa".

Un relato fundamental de ello sería la colonización antioqueña, como hecho histórico determinante de las valoraciones positivas atribuidas a los paisas por ellos mismos ${ }^{19}$.

18 Este punto hace referencia a la relación del documento analizado, con textos anteriores sobre la misma temática, pero que están por fuera del recorte establecido para esta aproximación.

19 La "verraquera", la heroicidad, la laboriosidad, entre otros. 
No son pocos los estudios, investigaciones, textos, artículos y libros dedicados a abordar diferentes temas que tienen lo paisa como importante eje de análisis, indagando sobre los orígenes, los rasgos distintivos y las características de este colectivo. Tal situación no es de extrañar, considerando que se trata de una región que concentra una importante parte del poder económico y político en el ámbito nacional, mostrando claramente lo planteado por Bartolomé (2006), respecto a que las dinámicas de producción de poder simbólico se corresponden con la acumulación de poder político y económico.

En ese mismo sentido, a partir de los textos abordados, es evidente la responsabilidad de las producciones académicas en replicar y brindar cierto sustento a las epopeyas o mitos autorreferenciales de los paisas, pues se trata de producciones revestidas de un "estatus científico". Esta situación es anticipada dentro de los mismos textos analizados, uno de los cuales expone que en Colombia no se ha estudiado a otro colectivo con tanta profundidad desde la historia, la antropología, la sociología y la economía, como al grupo sociocultural conocido como paisas o antioqueños (Vásquez Lara, 2013, p. 13).

No obstante, pese a la vasta cantidad de estudios sobre lo paisa, son notorias las lagunas, baches y silenciamientos que estos relatos presentan. Según Hall (2010) tales ausencias son iguales o más importantes que las representaciones mismas, toda vez que muestran, quienes y sobre quienes se ha ejercido el poder. En esa medida, podemos entender que no es gratuita la ausencia de relatos sobre las violencias sistemáticas ejercidas por paisas dentro y fuera de su territorio, y que han sido legitimadas por los centros de poder, favoreciendo la apropiación y usurpación de territorios a lo largo y ancho del país (insumo fundamental del conflicto armado colombiano).

De igual manera, en los trabajos académicos sobre los paisas, tras la lectura y análisis de los textos seleccionados, percibimos que en ninguno de ellos se problematiza y profundiza suficientemente el tema de los conflictos con sus "otros". Por ejemplo, el conflicto de los paisas con los caucanos, esbozado en la reflexión de Vásquez Lara (2013); con los chocoanos (Serna Botero, 2013); o con las comunidades costeñas en la frontera con Antioquia durante el proceso de colonización (Pimienta Betancur, 2007). Tales conflictos fueron prácticamente extirpados del relato hegemónico de la colonización antioqueña, pues se habla hasta el hastío de los territorios, pero poco o nada se dice de sus pobladores "no paisas". Una de las notables ausencias en el relato antioqueño es la de las comunidades negras e indígenas (Meneses, 2012). 
Dicha situación dialoga de cerca con los planteamientos de Albuquerque (2005), quien llama la atención sobre la necesidad de atender a las distintas representaciones construidas en el campo de la disputa económica, política y simbólica en los territorios de frontera.

Existen diversas situaciones que fracturan el relato paisa hegemónico, quebrantando las ideas de progreso y desarrollo. Tal es el caso de los fenómenos latentes en centros económicos de la región y que tienen que ver con la expansión y el dominio de agrupaciones armadas ilegales, con las prácticas extorsivas y de narcotráfico que no dan tregua en la región. Todo esto pone en vilo las míticas características de los paisas. Según Escobar (2007), los paisas en su intento de favorecer una retórica positiva de sí mismos, han olvidado y desdeñado gran parte de sus propios procesos, al mismo tiempo que han ignorado muchos otros.

Finalmente, encontramos que los relatos académicos recientes sobre el tema, durante el periodo establecido, pese a plantearse discontinuas y críticas de la representación previamente reproducida, se nutren a través de lo simbólico y de lo mítico de la versión de lo paisa que se consolidó durante el siglo XX, dando continuidad a un relato ya bien establecido.

Es interesante percibir la existencia de una red de significados que determinan la producción colectiva de sentido dando "cohesión" a este grupo social, al proveerlo de un sistema de interpretaciones, elementos y características comunes avaladas dentro del canon de verdad científico, provocando así, una adhesión afectiva capaz de moldear conductas e inspirar la acción de sus destinatarios.

Esta red de significados se ha gestado a parir del relato fundacional de la colonización antioqueña, alimentando las dinámicas paisas, forjando una fuente de imágenes de ensoñación y de gesta de la historia local (Jodelet, 1984), consolidada por el auto relato producido por las elites antioqueñas y reproducida, muchas veces sin ninguna crítica, por su academia.

Este trabajo invita a examinar los discursos reproducidos de forma homogénea y lineal sobre lo paisa (el hombre recio, blanco, amante de la ley y de Dios), que han conformado un eslabón clave en los procesos de construcción de una identidad colectiva, creando una serie de procesos sociales, políticos y económicos que exaltan el papel de la familia y la religión, al tiempo en que confrontan y estigmatizan lo no paisa, conllevando a posturas de racismo, segregación y discriminación. 
Simultáneamente, esto ha llevado a la justificación de la existencia de un campesinado y un empresariado motivados por una realización personal, que no problematiza la eliminación del otro mediante diferentes formas de violencia y prácticas al margen de la ley, justificando dicha eliminación como parte de una "cruzada" a favor de la exaltación de aquellos valores considerados característicos de los paisas como el progreso material.

\section{Reflexiones finales}

Las descripciones sobre lo paisa, producidas desde la academia con énfasis antropológico, durante los últimos 20 años, continúan apelando a una formación "especial" de naturaleza espiritual y síquica, social e histórica de los paisas. A pesar de reconocer, todas ellas, la estrategia de las elites en el siglo XX, que cimentó las bases de ese relato predominante, justificando sus actuaciones e intervenciones en los diferentes territorios aledaños.

Vemos que actualmente se continúa vanagloriando y privilegiando la posición afortunada desde las mismas valorizaciones del paisa frente a la representación negativa y estereotipada de los habitantes de otras regiones distintas de los centros de poder económico, político y de conocimiento como Medellín, Caldas, Pereira o Armenia.

Dicha situación, pese a las intermitencias, complicaciones y jerarquías existentes, expone lo ya mencionado por Gramsci (1924), frente al papel de los intelectuales en la construcción de las versiones hegemónicas de los grupos sociales a los que pertenecen. Se trata de una producción de poder en sí misma, que para el caso estudiado, legitimada desde la académica y aupada por el poder regional, ha incidido de forma determinante en las relaciones entre regiones y grupos sociales del país, modelando el escenario de participación en la nación. Aquí los paisas cuentan con legitimidad para incidir en las relaciones de poder en el orden nacional, habilitados por su imaginado pasado loable y de heroicidad sustentados en el discurso académico regional.

Las producciones académicas en muchos casos continúan homogenizando y reproduciendo prácticas discursivas, que no reconocen la diversidad de todos los componentes sociales de una nación, tendiendo a definir las identidades regionales de forma unívoca. En este caso, los relatos constitutivos del ser paisa, rememoran hasta el hastío la colonización antioqueña, hazaña que constituye la piedra angular de este discurso lleno de violencia, omisiones e invisibilidades. 
Cabe resaltar la necesidad de emprender pesquisas que deconstruyan los relatos y mitos fundacionales de nuestras naciones, repletos de hombres, héroes y hazañas, apostando por perspectivas que nos permitan reformular las historias que nos constituyen en clave de la diversidad de voces que somos; apuntando hacia versiones que nos permitan encontrar lugares dignos para todos y reflejarnos con menos interferencias en los otros.

\section{Referencias}

Albuquerque, J. (2005). Campesinos paraguayos y "brasiguayos" en la frontera este del Paraguay. En R. Fogel y M. Riquelme (ed.), Enclave Sojero, Merma de Soberanía y Pobreza (pp. 157-190). Asunción: Ediciones CERI.

Anderson, B. (1983). Comunidades imaginadas. Reflexiones sobre el origen y la difusión del nacionalismo (Trad. Eduardo Suárez). México: Fondo de Cultura Económica.

Antonio Manuel, F.S.C. (1962). Historia y Geografía elementales del Departamento de Antioquia. Medellín: Editorial Bedout.

Arango, L. (1991). Mujer, religión e industria. Medellín: Ediciones Universidad de Antioquia.

Arcila, M. (2006). El elogio de la dificultad como narrativa de la identidad regional en Antioquia. Historia Crítica, (32), 38-66.

Bartolomé, M. (2006). Los laberintos de la identidad: procesos identitarios en las poblaciones indígenas. Avá Revista de Antropología, (9), 28-48.

Calle, F. y Correa, J. (2002). El ethos antioqueño: Soporte moral para la creación, desarrollo y conservación de empresas. Semestre Económico, 5(10), 1-20.

Díaz, P. (2012). El alma colombiana. Idiosincrasia e identidades culturales en Colombia. Hallazgos, 9(18), 119-141.

Escobar, J. (2012). La historia de Antioquia, entre lo real y lo imaginario. Un acercamiento a la versión de las élites intelectuales del siglo XIX. Revista Universidad EAFIT, 40(134), 51-79.

Fajardo, L. (1966). La moralidad protestante de los antioqueños: Estructura social y personalidad. Cali: Universidad del Valle.

González, H. (2003). Pertinencia de la cultura paisa en la administración de empresas. Semestre Económico, 6(12), 1-12.

Gramsci, A. (1974 [1924]). Los cuadernos de la cárcel (Trad. Ana Palos). México: Universidad Autónoma de Puebla - Ediciones Era.

Hall, S. (2010). Identidad y representación. En E. Restrepo, C. Walsh y V. Vich (ed.), Sin Garantías: Trayectorias y problemáticas en Estudios Culturales (pp. 339-482). Bogotá: Editores envión.

Hermelin, M. (1991). Geografía física de Antioquia. Medellín: Suramericana.

Hernández, G. (2012). Cuatro aportes desde la antropología para comprender la emigración. Universitas humanistica, (74), 35-56. 
Jodelet, D. (1984). La representación social. Fenómenos, concepto y teoría, En S. Moscovici (ed.), Psicología social II. Psicología social y problemas sociales (pp. 469-495). Barcelona: Editorial Paidós.

Martí, E. y Pozo, J. (2000). Más allá de las representaciones mentales: la adquisición de los sistemas externos de representación, Infancia y Aprendizaje. Journal for the Study of Education and Development, 23(90), 11-30.

Meneses, Y. (2012). Comunidad Afro de Medellín y Antioquia: La Cuestión de los aportes, la Ideología Paisa y Organización Social-Comunitaria Autónoma. Universidad de Antioquia, Medellín.

Nates, B. (2009). Pensar el mundo, practicar el entorno. Etnografías y reflexiones desde una antropología de las territorialidades. Revista de Dialectología y Tradiciones Populares, 64(1), 277-296.

Ocampo, J. (1993). Las fiestas y el Folclor en Colombia. Bogotá.: El Áncora Editores.

Parra, J. (2014). Arqueología del Chucu-chucu. Medellín: Instituto Tecnológico Metropolitano.

Parra, J. (2017). Deconstruyendo el Chucu-chucu. Auges, declives y resurrecciones de la música tropical colombiana. Medellín: Instituto Tecnológico Metropolitano.

Pimienta Betancur, A. (2007). La configuración de la identidad local en la diversidad cultural: el caso de Caucasia. Revista Palobra, 8(8), 60-77.

Posada, C. (2011). La raza negra en Colombia: antioqueños y chocoanos. Estudios de literatura colombiana, (12), 105-109.

Saldarriaga, R. (2012). El paisa y sus orígenes. Medellín: Editora Nuevomundo.

Serna Botero, S. (2013). En blanco y negro Paisas y chocoanos en Quibdó (tesis de maestría). Pontificia Universidad Javeriana, Bogotá, Colombia.

Twinam, A. (1982). Mineros, comerciantes y labradores, las raices del espíritu empresarial antioqueño, 1763-1810. Austin, USA: Universidad de Texas - Fondo Rotatorio de Publicaciones FAES.

Vásquez Lara, C. (2013). Los imaginarios de la colonización antioqueña desde 1860 hasta 1930 en la zona del Eje Cafetero una visión antropológica. Revista Educación y Pensamiento (20), 7-30.

Villegas, F. (2003). Origen genético del pueblo antioqueño y su triple mestizaje. Fondo Editorial Biogénesis, (2), 37-49.

Villegas, F. (2003). El antioqueño, un pueblo diferente. Fondo Editorial Biogénesis, (2), 19-36. 